\title{
The nature of sleep examined via the science of sleep
}

\author{
This article was published in the following Dove Press journal: \\ Nature and Science of Sleep \\ 8 June 2011 \\ Number of times this article has been viewed
}

\section{Mohammad Viqar Hussain Steven Andrew Shea}

Division of Sleep Medicine, Harvard Medical School and Brigham and Women's Hospital, Boston, MA, USA
Correspondence: Steven Andrew Shea Division of Sleep Medicine, Harvard Medical School, Brigham and Women's Hospital, 22I Longwood Avenue, Boston, MA 02II 5 USA

Tel +l 6177325103

Fax +I 6172780683

Email steven_shea@hms.harvard.edu
The phenomenon of sleep is so curious from almost every vantage point: historical, cultural, scientific, and medical. The Nature and Science of Sleep is a new journal that aims to publish original research and reviews that will help unravel the mysteries of sleep, and improve our understanding of sleep disorders in humans.

The success of a new journal can be unpredictable. Ideally there would be a high threshold for publication of only important and robust findings or very well considered reviews, yet the best scientists and authors may be reluctant to put their best work in a new journal because there is a perceived risk that the new journal will not become popular. However, publishing in the Nature and Science of Sleep provides authors with numerous advantages. First, we are committed to making this journal a success. As an example of this, the Nature and Science of Sleep has one of the fastest turnaround times for peer review and editor's approval among medical journals, with an average review plus editorial decision in less than 2 weeks and online publication soon after. Second, we provide open access publishing so that all papers are freely available to anyone in the world directly from the website. Third, our editorial board comprises many of the world's distinguished scientists within the field of sleep research and sleep medicine, which provides a great foundation for this journal. Fourth, we anticipate that in the near future all publications within this journal will be available through PubMed and other searchable databases.

In its first full year of its publication, the Nature and Science of Sleep has enjoyed considerable and increasing popularity with the publication of several impressive original research articles and review articles that have begun to shed light on the relationships between sleep and the endocrine system, obesity, sleep apnea, periodic limb movement disorder, restless legs syndrome, circadian disruption, and a number of relatively novel treatments for insomnia. ${ }^{1}$ In addition, in the coming weeks a 'white paper' regarding implementation of the recent US Institute of Medicine recommendations on resident physician work hours will be published in the journal. ${ }^{2}$ As of April 7th 2011, there are 28 articles published, and there have been $\sim 80,000$ views of the website with $>20,000$ views of individual papers. For comparison, the well-established high impact Public Library of Science general online journal "PLOS One" published 20 research articles 1 year ago on April 7th 2010, with a median of 1,524 views per article over 1 year. Across the same period, the articles that Nature and Science of Sleep published for 1 whole year had a median of 1,331 views per article. Thus, although these are still early days, we believe this to be a very encouraging metric that testifies to the interest in 
and quality of our new journal, and the likelihood of growing success for the Nature and Science of Sleep.

Approximately one-third of our lives are spent asleep even though this period of unconsciousness can be dangerous due to a reduced ability to react to emergent threats. Moreover, every species studied has a rest-activity cycle. These facts surely testify to the almost unrelenting necessity for sleep. But, there are many pivotal questions about sleep that remain unanswered. For example, is there a single primary function of sleep, or are there many functions that require sleep? In this regard, it seems plausible that the primary function of sleep is quite separate from the many obvious physiological and psychological improvements that are associated with adequate sleep (such improvements could reflect the body merely utilizing the occurrence of sleep to optimize these functions). How much can we reduce the amount of sleep without compromising these functions? How is the function of sleep linked to the protective danger signal of inadequate sleep, namely sleepiness? Can we objectively quantify the physiological signal of 'sleep drive' needed to effect sleep homeostasis? Can pharmacological or behavioral manipulations be used to 'cheat the system' and avoid dysfunction despite ostensibly inadequate hours of sleep?

Regarding the title of the journal: we consider the "nature of sleep" to reflect the observable characteristics of sleep such as altered posture, closed eyes, reduced activity, temperature, heart rate and blood pressure, distribution of sleep stages across the night, differences in sleep patterns across the human lifespan and across species, the amount of 'rebound' sleep required following sleep loss (sleep homeostasis), and the difficulty of sleeping at certain times of day (ie, during the circadian daytime). On the other hand, we consider the "science of sleep" as attempts to explain the nature of sleep from a mechanistic standpoint, often using experimental interventions, predictions, plus inferential statistics to test specific hypotheses, rather than observation alone. An increasing number of important scientific findings in the area of sleep regulation have occurred over recent years including identification of neurotransmitters and neural circuits that help control sleep and wakefulness, as well as the psychological and physiological functions that are improved by sleep, such as memory consolidation, vigilance, mood, glucose homeostasis, and immune function. On top of this, and spanning both the nature and science of sleep, is the field of sleep disorders medicine. Sleep disorders, such as insomnia and sleep apnea, affect millions of individuals. Although some therapies for specific sleep disorders can improve sleep and overall psychological and physiological well-being, in almost all cases the current therapy for sleep disorders is suboptimal, and more research and clinical studies are sorely needed in this area.

We encourage you to submit your best original research papers, clinical studies, reviews, case reports, technical evaluations, guidelines, and expert opinions for publication in the Nature and Science of Sleep. With your help, we will better understand the reasons for our mysterious but inevitable nightly retreat into unconsciousness, and explore methods or therapies that will help everyone achieve the sleep they need.

\section{References}

1. Hussain MT, Shea SA. Wake up to insomnia:future approaches to the management of insomnia. Nat Sci Sleep. 2011;3:1-3.

2. Blum AB, Shea S, Czeisler CA, Landrigan CP, Leape L. Implementing the 2009 Institute of Medicine recommendations on resident physician work hours, supervision, and safety. Nat Sci Sleep. 2011. In press.
Nature and Science of Sleep

\section{Publish your work in this journal}

Nature and Science of Sleep is an international, peer-reviewed, open access journal covering all aspects of sleep science and sleep medicine, including the neurophysiology and functions of sleep, the genetics of sleep, sleep and society, biological rhythms, dreaming, sleep disorders and therapy, and strategies to optimize healthy sleep. The journal welcomes

\section{Dovepress}

original research, clinical \& epidemiological studies, reviews \& evaluations, case reports and extended reports. The manuscript management system is completely online and includes a very quick and fair peerreview system, which is all easy to use. Visit http://www.dovepress.com/ testimonials.php to read real quotes from published authors. 